\title{
Familial Mediterranean Fever and Armenian Genocide: qualitative study and literature review Armen Nersisyan*
}

Address: National Institute of Public Health of the Republic of Armenia, Armenia

* Corresponding author

from International Society on Brain and Behaviour: 2nd International Congress on Brain and Behaviour Thessaloniki, Greece. 17-20 November 2005

Published: 28 February 2006

Annals of General Psychiatry 2006, 5(SuppI I):S3 I2 doi:I0.I I86/I744-859X-5-SI-S3 I 2

\section{Background}

The first authors describing the Familial Meditteranan Fever Reiman, Squier, Mamou, described it after the Armenian Genocide among the Armenians who were inhabited in Lebanon (Anchar a village consisting of people exceptionally from Musaler) and in the United States. Other authors Nasaretian 1995 considered the disease to be an "adaptation disease". This multi-symptom, enigmatic and till the present undiscovered disease needs to be investigated from the viewpoint of posttraumatic stress disorder, as far as it can still last many years.

\section{Materials and methods}

125patients suffering from underwent clinical-psychopathological investigation, meantime were investigated the materials referring Familial Mediterranean Fever from the viewpoint of posttraumatic stress disorder (PTSD).

\section{Results}

The results of the investigation show that the parents, the grandparents of the $85 \%$ of the patients are immigrants: The attack is a flashback - which is realized in such a stress situation, directed to the patient, personality, family the place of residence, reproducing what the organism had in the genetic memory connected with the trauma in the past, to which in the present it responses with its defensive mechanisms- fever, aseptic inflammation etc. Alexithymia is explained as a condition masked from, chronic morbid grief and depression. We connect the mechanisms causing alexithymia with extremely powerful stress impulse - the Armenian genocide, with its consequences as post traumatic stress disorder.

\section{Discussion}

Familial Mediterranean Fever can be caused by powerful stress (genocide), genetically transferring untreated post- traumatic stress disorders (inter- attack period), flashbacks (pre-attack period), fever, aseptic inflammation (attack period), which presents defending factors for regulating the homoeostasis and at the present acts not adequately and is the main symptom of this disease. The discovery of alexithymia with patient suffering from Familial Mediterranean Fever, with accompanied, anxity and depression, also proves that the nature of FMF belong to the class of psychosomatic disorderse. 